\title{
The effect of COVID fatigue on mental health in the public sector organizations: exploring compassion as a mediator
}

\author{
Shilpi Kalwani $(\mathbb{D}$
}

Accepted: 26 October 2021/Published online: 25 November 2021

(C) Indian Institute of Management Calcutta 2021

\begin{abstract}
This study examines the impact of COVID fatigue on mental health amidst the pandemic. In particular, it tries to understand the mediating role of compassion in the equation between COVID fatigue, corona anxiety, social support, and mental health. Systematic review was conducted to understand the interrelationship among chosen variables. Hierarchical regression was used as a tool of empirical evidence for the derived interrelationships. The results from a survey of 307 white-collar employees from public sector organizations in India confirmed the mediating role of compassion on mental health. The results state that a unit change in the dependent variables of COVID fatigue, corona anxiety, and social support can have an impact of $9.7 \%$ on the mental health quotient. It was also found out that introducing a unit of compassion in the equation will mediate the impact to $3.7 \%$. In this study, $61.1 \%$ of participants were categorized as psychologically fatigued and 38.9\% as psychologically non-fatigued. Implications for the theory and practice of compassion are discussed, and future research directions offered.
\end{abstract}

Keywords COVID fatigue - Compassion · Corona anxiety $\cdot$ Social support $\cdot$ Mental health $\cdot$ Corona pandemic

S. Kalwani (

Department of Management, BITS Pilani, Pilani,

Rajasthan 333031, India

e-mail: shilpibsp@gmail.com

\section{Introduction}

The outbreak of the COVID-19 in Wuhan, China, has affected the economy globally (MacIntyrea 2020; Newey \& Gulland 2020). The dramatic impact of pandemic left the workplaces with the inevitable practice of "unlearning and relearning" (Lund et al. 2020). The workplaces on the one hand are battling with emergent change in work practices and the employees with stress and mental health concerns (Brosschot et al. 2005; Shigemura et al. 2020; Kniffin et al. 2021). The disease has already taken hold in Europe, the USA, and Southeast Asia and is beginning to wreak havoc in Africa and South America. India is battling with the second wave of Corona. The trends demonstrate that the first wave at its peak recorded approximately 1,00,000 new cases every day. The second wave at its peak has recorded approximately 3,00,000 new cases every day (Kamraju 2021). The COVID active cases and death statistics in the country as of 22 June 2021 are 6,62,521 and 3,89,302, respectively (MOHFW 2021). The decreasing count of active cases since the peak of the second wave in April 2021 has been due to the introduction of a mass vaccination program in India. A total of 28,87,66,201 people have been vaccinated by 22 June 2021 (MOHFW 2021). The concept of COVID fatigue can be defined as presumed tendency for people naturally to become tired of the rules and guidance they should follow to prevent the spread of COVID-19 (Michie 2020). It has 
been more than a year battling the chaos and uncertainty at the workplaces, and the organizations have started stinking of the COVID fatigue. The severity of the pandemic and the anticipated painful aftermath are the major reasons behind this study.

Severe lockdowns were imposed in India with Government Organizations functioning at 50\% capacity and private organizations adopted work from home routine (DOPT 2021). This was because public sector organizations form the backbone of the Indian economy (Pandey and Saxena 2020). People working in such Government organizations are working under immense fear and pain. They are at such a high risk of transmitting the virus back to their families and loved ones (Wong et al. 2020). This was the major reason behind considering a public sector organization for the study. The numbers are alarming. Organizations need to be prepared with an effective coping mechanism to deal with the present challenges and the aftermath of this pandemic. During this crisis, the support from superiors, peers, and compassion at the workplace can work wonders to release the mental burden of employees (Banerjee 2020). The paper tries to understand the impact of COVID fatigue on employees and how compassion mediates the equation in the presence of other substantial corona-related factors. The variables such as COVID fatigue, corona anxiety, social support, mental health, and compassion have been chosen after an extensive literature review to understand crisis management in organizations. A preliminary literature review was conducted for the year 2018-2020 to understand the most substantial coronarelated variables. This preliminary review of the literature led to the choice of five most relevant corona-related variables which can help develop an efficient coping mechanism in organizations.

\section{Literature review}

Workplace fatigue

Most of the literature concerning occupational health and safety risks is associated with sleepiness and fatigue as the major cause of concern at workplace (Rosekind 1999; Akerstedt 1988; Lauber and Kayton 1988; Mitler et al. 1994; Morgul et al. 2021). Fatigue at work is directly related to sleepiness at work, reduced alertness, impaired neurobehavioral performance, and increased risk of accident and injury at work (Tilley et al. 1981, 1982). The concept of workplace fatigue is not a new one. It exists since the time man was first placed in an environment where the demand for food and shelter exceeded an easily available supply. However, things took a drastic turn after the invention of electric light. Before that, illumination for working was provided only by fires, candles, or gas lamps and thus working hours were limited to daytime (Newton et al. 2010). These sources did not provide adequate intensity of light needed for detailed oriented work. The introduction of the electric light at the workplace provided levels of illumination equal to or better than daylight. Post that, work hours have never been limited by daylight. In 1910, prior to the widespread use of electric lights at workplace, the average sleep time of an employee was $9 \mathrm{~h}$. Post that, the average sleeping time has reduced to $7-7.5 \mathrm{~h}$, being a major cause of workplace sleepiness and fatigue (Coren et al. 1997).

Fatigue was been mostly researched in clinical studies in the early 1900 . The concept of psychological fatigue was the prime focus of conceptual and empirical studies concerning clinical population (Rosekind et al. 2010). Psychological fatigue is caused by inadequate rest, physical effort, or mental strain unrelated to a specific medical condition. The shift of focus from physical fatigue to psychological fatigue and the change of epicenter from clinical to nonclinical population were the key points of revolution in the studies conducted in and post 2000s (Noy et al. 2011; Dembe et al. 2008; Vegso et al. 2007).

The studies post 2000s also had a substantial linkage of fatigue to positive emotions and positive interventions at the workplaces, though the number of such studies has been very limited. The next section explains the relationship between COVID fatigues and positive emotions at workplace in detail.

COVID fatigue and positive emotions at the workplace

Emotions are the building blocks of humanity. They play a substantial role in decision making and communicative experiences at individual, group, and organizational level (Miller 2007). Human emotions have always been directly proportional to productivity at workplace. Positive emotions at workplace have always helped improve the employee productivity 
(Seppala and Cameron 2015). Pandemic has not only threatened the physical health quotient of an individual employee but has degraded the quality of healthy workplace culture (Barsade and Knight 2015). COVID fatigue is slowly seeping into the emotional quotient of the workplaces. Social distancing has initiated the ripples of emotional distancing as well. With the workplaces thriving for economic stability and building deeper emotional connections at work simultaneously, the efficacy to attain the balance is still questionable. With so much noise about the economic slowdown, are we filtering out the mental slowdown? Are we soon entering a mental health crisis? Is there enough communication toward flattening the mental health curve? These are some of the critical questions that form the foundation of this research.

$13 \%$ of global burden of diseases is borne by depressive and anxiety disorders (Choda 2020). Mental health has been the primary cause of concern as per to the global health statistics (Erceg et al. 2020). The pandemic has negatively affected the mental health of $56 \%$ of adults (Kaiser et al. 2020). December 2019 has been beginning of this dreadful episode. The virus started spreading at a multiplied rate across boundaries causing threat to human life (Erceg 2020). Originated from a city called Wuhan in China, it spread across the nation. The impact of this was so drastic that on 30 January 2020, WHO announced COVID-19 epidemic as Public Health Emergency of International Concern. As of May 24, 2020, there have been 5.2 million cases, with 337,736 deaths reported to WHO globally (Sharma et al. 2020).

Social, economic, and psychological concerns

Since the outbreak, the major concern for economists all around the world was the financial havoc it had created (Tooze 2020). But the focus shifted when it started taking a toll on people's mental and physical health (Ma et al. 2020). There is so much information floating around. Newspapers, media, online portals are all trying to spread awareness with the right intent. But this overdose of information is creating a sense of panic and obsession with the pandemic (Smith 1976; Kumar and Somani 2020). These obsessions or mental health concerns can have serious repercussions. Mental health concerns not only lead to mental disorders and illnesses, but to serious social problems such as physical self-harm and harm to others, criminal behavior, suicide, unproductive behavior at work, and many more (Choda 2020). The rising number of cases pertaining to domestic violence, abuse, crimes, and suicides is substantial proof of the degradation of mental health quotient during the pandemic. A major aspect of maintaining a healthy mental health quotient lies in the work-life balance. Work consumes a major part of one's life, and hence, the constantly changing structures and routines at work have been a tedious task during the pandemic.

The outbreak of COVID-19 has bought with it numerous changes in the working pattern. Flexible work schedules are need of the hour. But are these new flexible working patterns safe for employee mental health? The psychosomatic effects of the corona anxiety and fatigue have also been a subject of concern for the researchers in the domain of mental health (Nardi and Cosci 2021). A major source of emotional exhaustion and depression in employees is high job demands. Work constitutes a major part of one's life, and hence, well-being at work is of prime importance. These flexible working patterns are blurring the lines between work-life parameters (Rofcanin and Anand, 2020). A major rise in stress among employees is observed when there is a low job control. What better trigger than the ongoing pandemic? The outbreak was so uncertain, and the organizations were so unprepared that the emotional cost associated with such low job control situation is very high (De Lange et al. 2004).

\section{Compassion}

Compassion is a human emotion that is a response to suffering and motivation to act (Strauss et al. 2016). Looking at the historical evidence, compassion has roots in disciplines such as religion, philosophy, and sociology. Through the evolution of society over years, it is still believed that the essence of compassion has remained unchanged (Nussbaum 1996). The mention of compassionate acts was present in Judaism, Buddhism as well as Biblical Traditions. Though the concept of compassion is 2500 years old as per Buddhist traditions, the literary work started evolving after 1871 (Kanov et al. 2004). The evolution of compassion, varied definitions, and the conceptualization of the concept are chronologically explained below (Table 1) ( 2004). 
Table 1 Definition and conceptualization of compassion

\begin{tabular}{|c|c|c|}
\hline $\begin{array}{l}\text { S. } \\
\text { No }\end{array}$ & Author & Definition \\
\hline 1 & Darwin (1871) & $\begin{array}{l}\text { "those communities which included the greatest number of the most sympathetic members would } \\
\text { flourish best, and rear the greatest number of offspring" (p. 130) }\end{array}$ \\
\hline 2 & Lazarus (1991) & "Being moved by another's suffering and wanting to help" (p. 289) \\
\hline 3 & Dalai Lama (1995) & "An openness to the suffering of others with a commitment to relieve it" \\
\hline 4 & Neff $(2003 b)$ & $\begin{array}{l}\text { "being open to and moved by one's own suffering, experiencing feelings of caring and kindness } \\
\text { toward oneself, taking an understanding, nonjudgmental attitude toward one's inadequacies and } \\
\text { failures, and recognizing that one's own experience is part of the common human experience" (p. } \\
\text { 224) }\end{array}$ \\
\hline 5 & Kanov et al. (2004) & $\begin{array}{l}\text { "exists when members of a system collectively notice, feel, and respond to pain experienced by } \\
\text { members of that system" (p. 822) }\end{array}$ \\
\hline 6 & Gilbert (2009) & "A deep awareness of the suffering of another coupled with the wish to relieve it" ( p. 13) \\
\hline 7 & Goetz et al. 2010 & $\begin{array}{l}\text { "the feeling that arises in witnessing another's suffering and that motivates a subsequent desire to } \\
\text { help" (p. 351) }\end{array}$ \\
\hline 8 & Pommier (2010) & $\begin{array}{l}\text { Compassion can be defined by three elements: kindness, mindfulness, and common humanity } \\
\text { (Strauss et al. 2016) }\end{array}$ \\
\hline 9 & $\begin{array}{l}\text { Feldman and Kuyken } \\
\text { (2011) }\end{array}$ & $\begin{array}{l}\text { "an orientation of mind that recognizes pain and the universality of pain in human experience and the } \\
\text { capacity to meet that pain with kindness, empathy, equanimity, and patience" (p. 145) }\end{array}$ \\
\hline 10 & DOH (2012) & Compassion has even been defined as "intelligent kindness" (p.13) \\
\hline
\end{tabular}

Theory of compassion (Adam Smith, 1759)

The theory that forms the very base of compassion is "Adam Smith's Theory of Moral Sentiments." Crisp (2008) in studying and assessing the theory says that no matter how self-centered a person appears to be, there are some elements, which interest them to think about other people's happiness. Though one doesn't derive an advantage out of it, the mere thought of the happiness of other people makes it all pleasurable. The emotional experience associated with seeing the other person in pain, the misery of it touches us. It is also called the principle of "emotional contagion" (Crisp 2008, p. 240). The most common example of emotional contagion would be young babies who get distressed by the mere sound of other babies crying. This is the basis of compassion. As smith rightly describes it "original passions of human nature" (Smith, 1759, p. 2).

\section{Process of compassion}

Lilius et al. (2011) provides the process of compassion. Lilius further goes on to say that workplace compassion is a collective effort toward empathizing with an employee burdened with suffering. This process ignites a movement at the workplace which induces empathy, reduces pain, and co-creates a collective response. The three-step process of compassion by Lilius is described below:

1. Notice Suffering: To observe and notice whether employees are suffering in the workplace due to excessive stress or pain.

2. Felt Empathetic Concern: To empathize with the employees and make efforts to understand them better.

3. Compassionate Responding: Provide compassion care to support the suffering employees and make things better for them.

Although organizations have been portrayed as places with contradictory elements of rapid growth and suffering, some leaders help employees deal with painful situations, and some peers empathize and support their colleagues. Compassion in an organization emphasizes the need to be seen and heard in an organization (Frost et al. 2000). Most of the compassionate leaders listen and engage teams in day-to-day decision making so that none of the employees feel left out (Kahn 1993). Majority of studies and research conducted on workplace compassion talk about implementing compassion in leadership styles, 
communication networks, and decision making. Such studies "engage our minds but fail to engage our hearts" (Kanov et al. 2004, p. 810). The human experience is incomplete without the mention of empathy, kindness, suffering, and healing (Duan \& Hill 1996; Kellett et al. 2006). These studies fail to understand the facet of human emotions in organizations (Kanov et al. 2004; Frost 1999; Rozin 2001; Sandelands 1998, 2003; Weick 1999). Most of the researches has very little to contribute toward the human element of workplace compassion.

\section{Compassion as a positive psychology construct}

Occupational health hazard and compassion

Occupational illness is defined as "a condition that results from exposure in a workplace to a physical, chemical or biological agent to the extent that the normal physiological mechanisms are affected and the health of the worker is impaired" (Selvi, 2020). Occupational health hazard generally develops over a period of time. This may be due to a particular working pattern or exposure to certain chemicals or dust during the working hours. Another reason may be a certain outburst of a virus or bacteria such as the COVID-19. Compassion is not only associated with emotional support but also as a physical support. Research suggests that caring social networks have a positive physical impact on an individual. It leads to improved immunity, lower blood pressure, lower mortality, and greater creativity (Boyatzis et al. 2006). Most of the scientists have specified building immunity as a strong coping mechanism against fighting COVID-19. Poor occupational health could be one of an important stressors for mental health (Zabelina and Robinson 2010). The next section explains the severity of the mental health hazard in detail.

\section{Mental health hazard and compassion}

The most severe impact of the Corona Pandemic has been on the mental health. It has been very difficult for organizations to carry out their day-to-day functioning with this rapidly spreading communicable pandemic. Organizations in such a difficult time have opted for flexible remote working options or work from home.
Most of the employees working from home are loaded with additional work pressures making it difficult for them to maintain the required work-life balance (Folkard and Tucker 2003; Chakravorty and Singh 2020). On top of it, the added stress of keeping loved ones safe from the pandemic is causing havoc in the mind. In such a situation, compassion can be used a very important positive intervention. Compassion care could be introduced to provide support to overburdened employees during the pandemic. Compassion is said to promote individual well-being and improve mental health (Cosley et al. 2010; Feldman and Kuyken 2011; MacBeth and Gumley 2012). It is also said that compassion helps social groups protect people who are feeling emotionally vulnerable or are suffering at a given point of time (Goetz et al. 2010). Gilbert's work on compassion is interlinked to his previous work on depression. He tried to understand depression from the perspective of self-criticism, shame, and powerlessness. He found compassion as a great tool to deal with the challenges of deteriorating mental health (Gilbert 1984, 2000).

\section{Other variables under consideration}

On the basis of amalgamation of literature studies over crisis management and positive interventions at the workplace, over the last 30 years, and the understanding of current pandemic, the following three allied variables have been chosen for the study.

\section{Corona anxiety}

Corona Pandemic has been widely studied in the light of economic and financial crisis. But the central theme derived from the literature review has been neglected. The dearth of studies discussing the impact of corona pandemic on mental health led Sherman A. Lee to develop a Corona Anxiety Scale. This scale measures the dysfunctional anxiety caused by the corona pandemic. The scale is a self-report mental health screener which is reliable and validated to generate useful insights (Lee 2020).

\section{Social support}

The outbreak of the pandemic brought with it a series of continuous lockdowns. Some people were stuck in these lockdown for months without their families and 
friends. Social support has been an extremely critical factor during the pandemic. The impact of social support on the physical, mental, and emotional health of an individual cannot be overlooked. Despite the relevance, there is a dearth of studies surrounding social support during corona pandemic. Hence, it is marked as an important variable for consideration (Veer et al. 2020).

\section{Mental health}

Corona pandemic has primarily caused a lot of threat to physical health of an individual. With so much discussion about the immunity and physical strength, the aftermath on mental health being overlooked? (Slemp et al. 2014). Researchers suggest that the impact of the pandemic on the physical health and immunity is temporary, and the major long-term implications would be on mental health (Kumar and Somani 2020; Arnout 2020; Pfefferbaum et al. 2020). Most often, there is an interchangeable use of terms like mental health, wellness, and well-being. The next section clearly defines the said concepts, their origin, and their growth over a period of time.

Evolution of literary work on mental health dates back to 1950s. After World War II, influential work on mental health began to be published. Seminal work on mental health was done by Jahoda in 1958. R. Grinker's studies of "homoclites" were the first empirical study of positive mental health in 1962. World Health Organization (2014) defines "Mental Health" as "a state of complete physical, mental and social well-being and not merely the absence of disease or infirmity." It is a dynamic state of internal equilibrium which enables individuals to use their basic cognitive and social skills to cope with adverse life events and maintain harmonious relationship between body and mind (Galderisi et al. 2015). In Indian origin, the first psychiatric mental health camp in India was organized in 1972, at Bagalkot, a taluka town of Mysore. Due to the rise in mental health disorders, this was the first time the concept of mental health was introduced in India. Decades later, the scenario has not altered substantially. There has been an improvement in the status of physical health, but mental health still suffers. About $14 \%$ of the global burden of disease is attributed to neuropsychiatric disorders. Hence, there arises a need to discuss and address the increasing concern in detail (Srivastava 2016).

\section{Methodology}

The methodology consists of both qualitative and quantitative analysis tools which are explained below in detail.

\section{Literature review}

Literature review was conducted in two parts. In the first part, a preliminary literature review was done for the past two years from 2018-2020 to understand the corona-related variables most affecting the organizations. The choice of five most substantial coronarelated variables was made. In the second part, a systematic literature review was conducted to understand the role of compassion as a mediating variable. The step-by-step process adopted for the systematic review is explained below.

\section{Identification of relevant literature}

The first step in the review was identifying the relevant literature on compassion for past 30 years from 1990-2020. The database of ISI Web of Knowledge was used for retrieval of records. Records from databases such as EBSCO, Taylor and Francis, Emerald, Springer, Elsevier, Wiley, ProQuest, and JSTOR are included in ISI Web of Knowledge database . Upon inspection, the keywords "compassion in organizations," "employees and COVID fatigue," "COVID-19 and organizations," and "crisis management in organizations" were used to manually search and retrieve the records. Along with the keywords, organizational behavior was selected as a domain in the filtering criteria.

- The database of ISI Web of Knowledge with the keywords "compassion" and "corona pandemic" was used for retrieval of literature. 24,500 papers were retrieved. The year criteria were set "1990-2020" as the inclusion criteria. The number of papers was reduced to 18,800 . The language criteria selected "English" as a language. The number of papers further reduced the number to 15,000 . The research areas were narrowed down to 
"Psychology," "Behavior Science," "Social Science," "Education Research," "Behavioral Sciences," "Communication," "Asian Studies," "Arts \& Humanities," "Developmental Studies" as the inclusion criteria. 8777 papers were retrieved. Out of which, 27 records were considered for review based on their relevance to the theme of the paper.

- Any record or literature retrieved outside the mentioned criteria of keywords, year, and language was excluded from the review. Grey literature was excluded from the review.

- The flowchart for PRISMA search strategy is explained below (Fig. 1).

Quantitative analysis

In order to see the impact of COVID fatigue, corona anxiety, compassion, and social support on mental health, with the mediating effect of compassion, the following instruments were selected:

- Corona anxiety was measured with a Corona Anxiety Scale (CAS). This scale was developed by Sherman A. Lee in April 2020. This is a five-item five-point Likert scale from 0 (not at all) to 4 (nearly every day). It captures dysfunctional anxiety symptoms for a period of last two weeks. A CAS total score $\geq 9$ indicates probable dysfunctional coronavirus-related anxiety. A score $\geq 9$ would require further clinical assessment (Lee 2020).

- COVID fatigue was measured with Fatigue Assessment Scale (FAS), which is a 10-item selfreported questionnaire designed by Miehielson et al. (2003) to assess general fatigue in the population. Five questions address physical fatigue and five questions mental fatigue (Drent et al.
Fig. 1 Flowchart for PRISMA Search Strategy

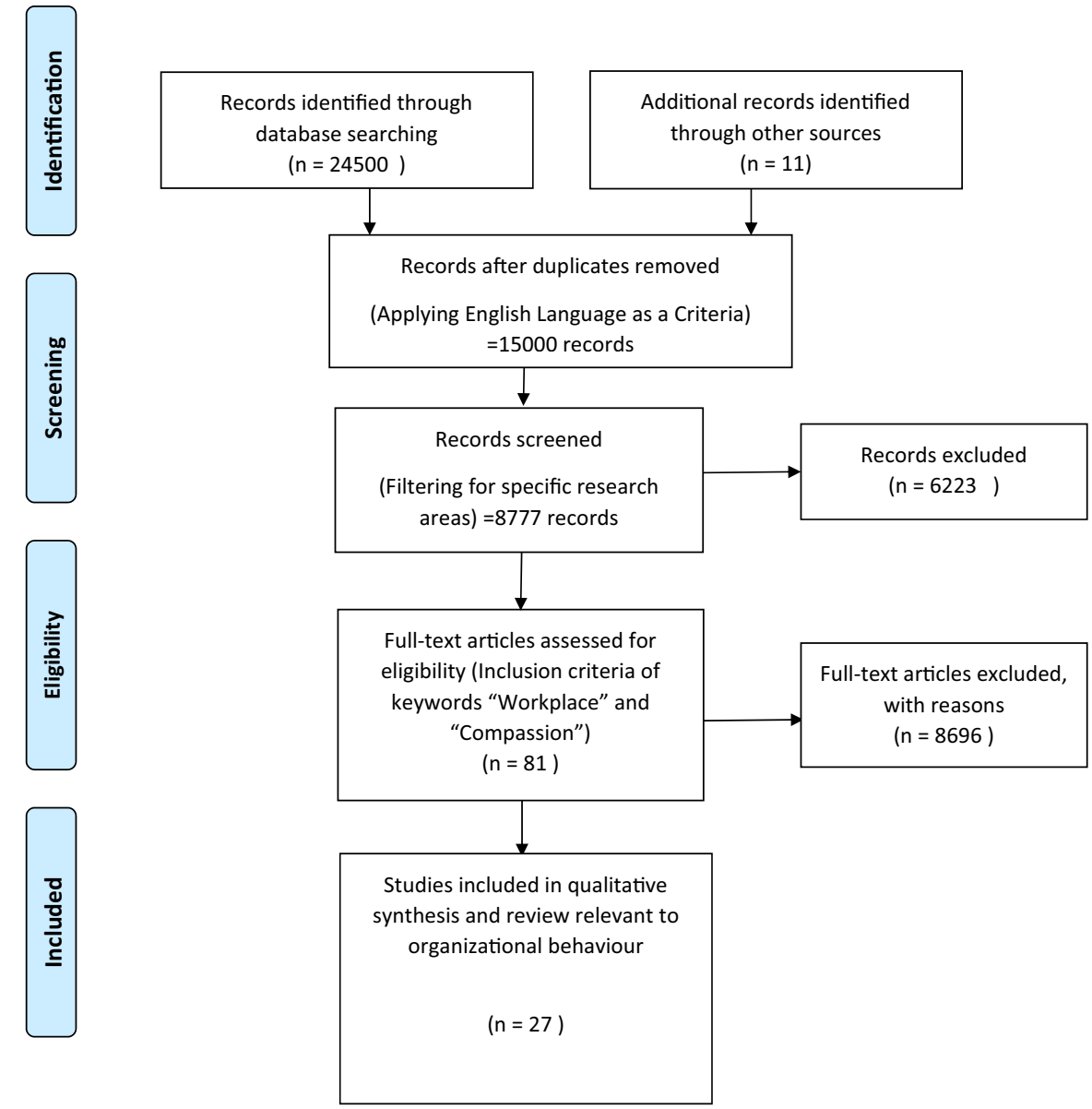


2012). In scoring, FAS scores $10-21=$ no fatigue (normal) and FAS scores 22-50 = fatigue.

- Compassion was measured by the Santa Clara Brief Compassion Scale (Hwang et al. 2008). It is a five-item, seven-point Likert scale, ranging from 1 (not at all true of me) to 7 (very true of me).

- Social support was measured by a single item in the questionnaire. The question asks an individual: "Who are you staying with during the pandemic? (1)alone (2)with friends (3)with family?". The scoring ranges from 0 (staying alone) to 2 (staying with family).

- Mental health (dependent variable) was measured by Job-related Affective Well-being Scale, (JAWS). This scale is developed by Katwyk et al. (1999). It is a 20-item, 5-point Likert scale. The scoring ranges from 0 (Never) to 5 (Extremely Often). It captures positive and negative jobrelated emotions for a period of past 30 days.

- Demographic variables like age, gender, educational qualification, and marital status were also recorded.

Statistical analysis

- Sample Characteristics: 400 responses were collected, out of which 307 responses were used for the statistical analysis. The incomplete and irrelevant responses were eliminated to arrive at the final number of 307 responses. The sample constituted of 195 males and 112 females. The age range of respondents was between 24 years and 50 years. $62 \%$ of the respondents recorded their marital status as married.

- Method of data collection: One time cross-sectional data survey was conducted. Questionnaire was floated online for a period of 1 month from 28 February 2020-30 March 2020. Doubts regarding the questionnaire or the process were addressed through email. Ethical protocols were followed while data survey and collection. Consent of respondents was taken, and they could back out from the survey at any point they felt link. The data were collected geographically from public sector organizations of states such as Chhattisgarh, Madhya Pradesh, and Gujarat from India. Nonprobability sampling technique was used for the survey.
- Statistical Tools: Linear regression and hierarchical regression were used as tools for statistical analysis. SPSS 16 software version was used for the analysis. The results of linear regression displayed that social support was comparatively less significant and less correlated than other variables and hence was omitted from further analysis. Based on the correlation of various independent variables with the dependent variable, COVID fatigue (OCS) and corona anxiety (CAS) were grouped as control variables and compassion as the predictor variable. This was done to understand the impact compassion has on mental health amidst the corona chaos.

\section{Results}

Qualitative results

\section{Research site}

Geographical segregation was done on the basis of the nationality of sample. $55.55 \%$ of the workplace compassion studies have been conducted in the USA, $18.51 \%$ in Canada, $11.11 \%$ in the UK, $7.40 \%$ in Spain, 3.7\% in Australia and Egypt. From Fig. 2, it is clearly evident that, in the selected sample, not a single study has been conducted on workplace compassion in India. The results are displayed in Fig. 2 and Table 2, respectively.

\section{Chronology as an indicator}

Positive psychology was established as a field in 1998. The authors wanted to see whether there was a pattern observed after 1998. However, no such pattern was observed. Maximum studies on workplace compassion globally have been conducted in the year 2006, 2011, and 2016. The percentages are $11.11 \%$ in 2006 and $14.81 \%$ in 2011 and 2016. The results are displayed in Table 2.

\section{Research-type indicator}

Conceptual studies include theoretical framework and analysis, empirical studies include statistical and empirical analysis, and review studies include review 
Fig. 2 Geographical segregation of identified literature
Workplace Compassion Studies (1990-2020)

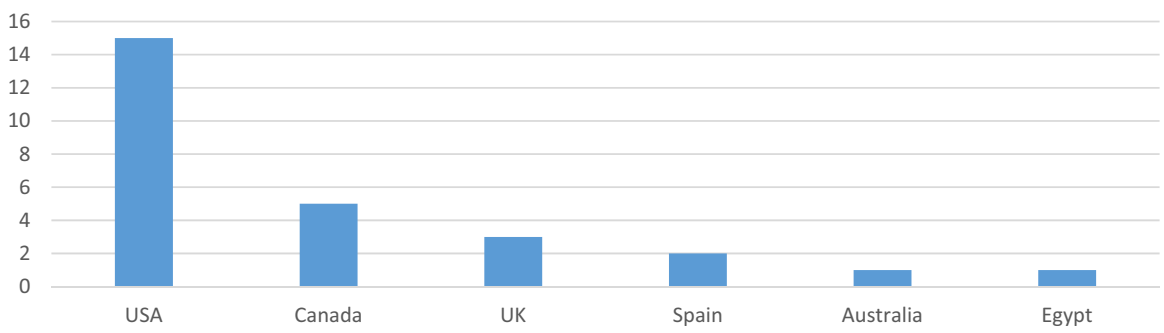

and analysis of multiple studies to derive patterns or insights. 55.55\% of compassion studies are conceptual, $33.33 \%$ compassion studies are empirical, and $11.11 \%$ studies are review studies. The results are displayed in Fig. 3 and Table 2, respectively.

\section{Quantitative results}

Quantitative results can be studied under two parts: the results obtained by linear regression (primary analysis) and hierarchical regression (secondary analysis).

\section{Linear regression}

SPSS 16 was used to run linear regression. Linear regression was run on all the independent variables to understand the effect on dependent variable of mental health. The obtained correlation coefficients are displayed in Table 3.

From the above correlation matrix, it is very clear that corona anxiety (CAS) is the most correlated with mental health, followed by COVID fatigue (CF) and compassion (COMP), whereas social support (SS) is negatively correlated with mental health. The obtained results from the linear regression analysis are displayed in Table 4.

The results indicate that $8.8 \%$ of the variance in mental health scores can be predicted from the variables COVID fatigue, corona anxiety, compassion and social support. This is an overall measure of the strength of association and does not reflect the extent to which any particular independent variable is associated with the dependent variable. The $\mathrm{F}$ test explains the variance involved between the predictor and outcome variable. With significance level as small as $p<0.001$, there is 0.1 chance of $F$ ration this large would happen. A variance of $8.405 \%$ is observed at this significance level. The $\mathrm{B}$ value explains the change in outcome resulting from a unit change in the predictor. Hence, with no trace of any independent variable, the mental health score is at 45.953 . When a unit of COVID fatigue is introduced, there is a change in mental health by 0.279 or $27.9 \%$. Again when a unit of corona anxiety is introduced, there is a change in mental health by 0.746 or $74.6 \%$. On the introduction of a unit of compassion, there is a change in mental health by 0.262 or $26.2 \%$. As and when a unit of social support is introduced, there is a change in mental health by (-) 0.471 or (-) $47.1 \%$. This gives us a basis for further conducting hierarchical regression. In hierarchical regression, the selection of the predictor variable and control variables is done on the basis of obtained correlation values and B values. To understand the mediating impact of compassion here, it is considered as a control variable. The impact of predictor variables such as COVID fatigue (CF), corona anxiety (CAS), and social support (SS) on mental health $(\mathrm{MH})$ is observed with and without the presence of compassion (COMP) as a mediator.

\section{Hierarchical regression}

In Model 1, compassion is controlled and the impact of COVID fatigue, corona anxiety, and social support is observed on mental health. In Model 2, the impact of COVID fatigue, corona anxiety, social support is studied in the presence of compassion. This is done to understand the mediating effect of compassion on mental health. The result of hierarchical regression is shown below (Table 5).

The results indicate that when compassion is controlled, the total variance caused in mental health is $9.8 \%$. The $\mathrm{R}$ square change value shows that when compassion is considered, it shows a mediating impact and the variance caused in mental health is reduced to $3.7 \%$. 
Table 2 Segregation of identified literature on the basis of research site, chronology, and research type

\begin{tabular}{lllll}
\hline Research Article & Author & Country & Type & Variables \\
\hline Compassion: The basic social emotion & Nussbaum (1996) & USA & Conceptual & Compassion \\
Compassion Versus Competitiveness: An & Cambridge (2001) & USA & Conceptual Compassion, \\
Industrial Relations Perspective on the & & & Competitiveness
\end{tabular}

Impact of Globalization on the Standards of

Employee Relations Ethics in the United States

Self-Compassion: An Alternative

Conceptualization of a Healthy Attitude Toward Oneself

The development and validation of a scale to measure self-compassion

Compassion in Organizational Life

Creating compassion and connection in the workplace

Explaining Compassion Organizing

Compassion Fatigue, Compassion Satisfaction, and Burnout: Reactions Among Employee Assistance Professionals Providing Workplace Crisis Intervention and Disaster Management Services

Compassion Fatigue, Compassion Satisfaction, and Burnout: Factors Impacting a Professional's Quality of Life

Compassionate communication at the workplace:

Explaining processes of noticing, connecting, and responding

Compassion and Beyond

The contours and consequences of compassion at work

Grief and compassion in the workplace

Self-Compassion, Self-Esteem, and Well-Being

Understanding compassion capability

Compassion in the landscape of suffering

Compassion Revealed

Emergent organizational capacity

for compassion

Understanding individual compassion in organizations: The role of appraisals and psychological flexibility

Compassion at work

The Compassionate Sexist? How Benevolent Sexism Promotes and Undermines Gender Equality in the Workplace

What is compassion and how can we measure it? Strauss et al. (2016) A review of definitions

and measures
Neff (2003a)

Neff (2003b)

Kanov et al. (2004)

O’Brien (2006)

Dutton (2006)

Jacobson (2006)

Sprang et al. (2007)

Miller (2007)

Crisp (2008)

Lilius et al. (2008)

Manns and Little (2011)

Kristin Neff (2011)

Lilius et al. (2011)

Feldman and Kuyken (2011)

Lilius et al. (2011)

Madden et al.(2012)

Atkins and Parker (2012)

Dutton et al. (2014)

Ivona and Lance (2016)

Kanov et al. (2017)
USA

Conceptual Self-Compassion

USA Conceptual Self-Compassion

USA Conceptual Compassion

Canada Conceptual Compassion, Compassion Organizing

USA Conceptual Compassion Organizing

USA Empirical Compassion Fatigue, Compassion Satisfaction, Burnout

USA Empirical Compassion Fatigue, Compassion Satisfaction, Burnout

USA Conceptual Compassionate Communication

UK Conceptual Compassion

Canada Empirical Compassion

USA Conceptual Grief, Compassion

USA Conceptual Self-Compassion, SelfEsteem and Well-Being

Canada Conceptual Compassion Capability

UK Conceptual Compassion, Suffering

Canada Conceptual Compassion

USA Conceptual Compassion, Organizational Capacity

Australia Review Compassion, Appraisals, Psychological Flexibility

USA Review Compassion

Canada Empirical Compassion, Gender Equality

UK Review Compassion 
Table 2 continued

\begin{tabular}{|c|c|c|c|c|}
\hline $\begin{array}{l}\text { Research Article } \\
\text { Is it ok to care? How compassion falters and is } \\
\text { courageously accomplished in the midst of } \\
\text { uncertainty }\end{array}$ & Author & Country & Type & Variables \\
\hline $\begin{array}{l}\text { Reflections on Workplace Compassion and Job } \\
\text { Performance }\end{array}$ & $\begin{array}{l}\text { Ghadeer Mohamed Badr } \\
\text { ElDin Aboul-Ela } \\
\text { (2017) }\end{array}$ & Egypt & Empirical & $\begin{array}{l}\text { Compassion, Job } \\
\text { Performance }\end{array}$ \\
\hline $\begin{array}{l}\text { A Study of Why Anomic Employees Harm Co- } \\
\text { workers: Do Uncompassionate Feelings Matter? }\end{array}$ & $\begin{array}{l}\text { Pablo Zoghbi-Manrique- } \\
\text { de-Lara \& Rita M. } \\
\text { Guerra-Báez (2018) }\end{array}$ & Spain & Empirical & $\begin{array}{l}\text { Compassion, Harming } \\
\text { Co-workers }\end{array}$ \\
\hline $\begin{array}{l}\text { Public Service Sector: The Compassionate } \\
\text { Workplace-The Effect of Compassion and } \\
\text { Stress on Employee Engagement, Burnout, and } \\
\text { Performance }\end{array}$ & Liat Eldor (2018) & USA & Empirical & $\begin{array}{l}\text { Compassion, Stress, } \\
\text { Employee Engagement, } \\
\text { Burnout, Performance }\end{array}$ \\
\hline $\begin{array}{l}\text { Does Ethical Leadership Motivate Followers to } \\
\text { Participate in Delivering Compassion? }\end{array}$ & $\begin{array}{l}\text { Pablo Zoghbi-Manrique- } \\
\text { de-Lara \& Mercedes } \\
\text { Viera-Armas (2019) }\end{array}$ & Spain & Empirical & $\begin{array}{l}\text { Compassion, Ethical } \\
\text { Leadership }\end{array}$ \\
\hline
\end{tabular}

Fig. 3 Segregation of identified literature on research type
Workplace Compassion Studies (1990-2020)

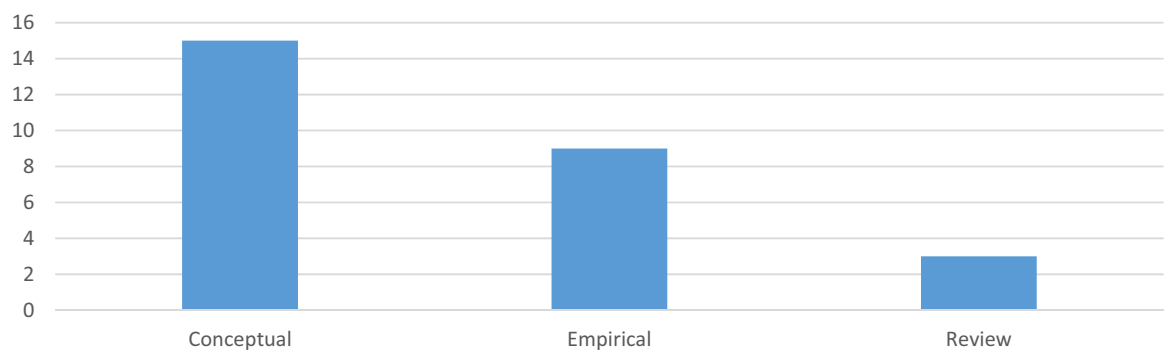

Table 3 Correlation matrix

\begin{tabular}{|c|c|c|c|c|c|}
\hline Correlation & $\begin{array}{l}\text { Mental Health } \\
(\mathrm{MH})\end{array}$ & $\begin{array}{l}\text { COVID Fatigue } \\
(\mathrm{CF})\end{array}$ & $\begin{array}{l}\text { Corona Anxiety } \\
\text { (CAS) }\end{array}$ & $\begin{array}{l}\text { Compassion } \\
\text { (COMP) }\end{array}$ & $\begin{array}{l}\text { Social Support } \\
\text { (SS) }\end{array}$ \\
\hline Mental Health (MH) & 1.000 & 0.199 & 0.236 & 0.192 & -0.030 \\
\hline COVID Fatigue (CF) & 0.199 & 1.000 & 0.580 & 0.044 & -0.59 \\
\hline $\begin{array}{l}\text { Corona Anxiety } \\
\text { (CAS) }\end{array}$ & 0.236 & 0.580 & 1.000 & -0.023 & -0.091 \\
\hline $\begin{array}{l}\text { Compassion } \\
\text { (COMP) }\end{array}$ & 0.192 & 0.044 & -0.023 & 1.000 & 0.173 \\
\hline Social Support (SS) & -0.030 & -0.059 & -0.091 & 0.173 & 1.000 \\
\hline
\end{tabular}

\section{Discussion}

The current study explains the relationship between COVID fatigue, corona anxiety, compassion, social support, and mental health in a country with cultural and social stigma toward mental health (Majumdar et al. 2020). The study explored the potential mediation of compassion in the equation. The results 
Table 4 Linear regression results

\begin{tabular}{|c|c|c|c|}
\hline Variables under analysis & Adjusted R square & F change & $\mathrm{B}$ value \\
\hline $\begin{array}{l}\text { COVID fatigue, corona anxiety, compassion, } \\
\text { social support, and mental health }\end{array}$ & 0.088 & 8.405 & $\begin{array}{l}45.953 \text { (Constant) } \\
0.279 \text { (COVID Fatigue } \\
0.746 \text { (Corona Anxiety } \\
0.262 \text { (Compassion) } \\
-0.471 \text { (Social Support) }\end{array}$ \\
\hline
\end{tabular}

Table 5 Hierarchical regression results

\begin{tabular}{lllc}
\hline Model Summary & R square & R square change & F Change \\
\hline Model 1 & 0.061 & 0.061 & 9.930 \\
Model 2 & 0.097 & 0.037 & 12.463 \\
\hline
\end{tabular}

indicate that a unit change in the dependent variables of COVID fatigue, corona anxiety, and social support can have an impact of $9.7 \%$ on the mental health quotient. A unit of compassion solely can mediate the equation and bring down the impact to $3.7 \%$. In this study, $61.1 \%$ of participants were found out to be psychologically fatigued. The statistics raise serious concerns. The long-term psychological consequences of this fatigue are still unclear (Townsend et al. 2021). In the past one year, many studies have indicated toward declining level of motivation at workplaces as a major concern (Newman 2021; Sasangohar et al. 2021). It is important to understand that it is not just the crisis that might impact the workplaces, but also the aftermath of it. The COVID survived workplaces will not just have to deal with the extrinsic factors such as the changing nature of role and responsibilities, but also intrinsic factors such as employee mental health and well-being quotient (Wostyn 2021). Hence, the importance of compassionate measures and compassion care cannot be overlooked at such critical time (Morgul et al. 2021). The aftermath will have the organizations being hit by three major setbacks of occupational health hazard, financial health hazard, and mental health hazard. These hazards could all be minimized with the positive intervention of compassion. There are traces in the literature that suggest use to compassion care as a positive intervention during crisis management.

\section{Conclusions and limitations}

This study makes an early attempt to explore the mediating role of compassion between COVID fatigue, corona anxiety, social support, and mental health. The empirical findings support the qualitative results stating that compassion mediates the equation. It has a significant impact on employee mental health quotient. However, this study has certain limitations, all of which lead toward future directions of research. The study has been conducted among public sector employees. For establishing the results, it can be tested in private sector organizations among varied sectors. The study has been conducted for a period of 1 month from 28 February 2020 to 30 March 2020 . The results may vary when a similar study is conducted pre- and post-different waves of the pandemic. Hence, to establish generalizability, the study could be tested across various time frames during and post the pandemic .

\section{Managerial implications}

The findings of the study provide substantial insights for researchers and management scholars, professionals, and organizational leaders. This study is one of its kind and among one of the earliest attempts to understand, conceptualize, and empirically establish workplace compassion as a substantial mediating variable in the futuristic post-COVID workplaces. One can foresee the long-term aftermath of this pandemic on the employee mental health (Nardi and Cosci 2021). The challenge to deal with the changing work structures is acting as a stressor for employee mental health (Li et al. 2021; Elraz 2017). Conceptually, this paper systematically reviews the literary work done in field of workplace compassion and 
mental health to understand the existing knowledge gaps in the literature. Compassion studies have shifted their focus from a human relations concept toward discourse and crisis management in the past few years. In such a scenario, this study will help researchers and practitioners understand, theoretically and empirically, the role of workplace compassion as a mediator toward the equation between COVID fatigue and employee mental health. Further, the empirical data can be collected at different phases of the pandemic, and post-pandemic to delve deeper into various facets of workplace compassion and their statistical significance. This research can serve as a foundation toward development and validation of a COVID fatigue scale. This research could lead the way for further substantial empirical research to combat the challenges to be faced by post-COVID workplaces.

\section{Acknowledgements None.}

Funding There is no funding associated with the research.

\section{Declarations}

Conflict of interest The author declares no conflict of interest.

\section{References}

Aboul-Ela GM, ElDin B (2017) Reflections on workplace compassion and job performance. J Hum Values 23(3): $1-10$

Akerstedt T (1988) Sleepiness as a consequence of shift work. Sleep 11:17-34

Arnout BA (2020) Investing scientific research outputs in light of crises and disasters:(COVID-19 crisis as a model). J Publ AffJ Publ Aff 20(4):e2356

Atkins PWB, Parker SK (2012) Understanding individual compassion in organizations: the role of appraisals and psychological flexibility. Acad Manag Rev 37(4):524-546

Banerjee D, Bhattacharya P (2020) "Pandemonium of the pandemic": Impact of COVID-19 in India, focus on mental health. Psychol Trauma Theory Res Pract Policy 12(6):588-592

Barsade SG, Knight AP (2015) Group affect. Annu Rev Organ Psychol Organ Behav 2(1):21-46

Brosschot JF, Pieper S, Thayer JF (2005) Expanding stress theory: prolonged activation and perseverative cognition. Psychoneuroendocrino 30:1043-1049

Boyatzis RE, Smith ML, Blaize N (2006) Developing sustainable leaders through coaching and compassion. Acad Manag Learn Educ 5(1):8-24

Cambridge C (2001) Compassion versus competitiveness: an industrial relations perspective on the impact of globalization on the standards of employee relations ethics in the United States. Ethics Behav 11(1):87-103

Chakravorty A, Singh P (2020) Work/family interference and burnout among primary school teachers: the moderating role of emotional intelligence. Decis 47:251-264

Choda N, Wakai K, Naito M, Imaeda N et al (2020) Associations between diet and mental health using the 12-item general health questionnaire: cross-sectional and prospective analyses from the Japan multi-institutional collaborative cohort study. Nutr J 19(2):1-14

Coren S. (1997). The sleepy society. In: Encyclopedia Britannica Yearbook of Science and the Future. Chicago, IL: Encyclopedia Britannica; 42-55

Cosley BJ, McCoy SK, Saslow LR, Epel ES (2010) Is compassion for others stress buffering? Consequences of compassion and social support for physiological reactivity to stress. J Exp Soc Psychol 46(5):816-823

Crisp R (2008) Compassion and beyond. Ethical Theory Moral Pract 11:233-246

Dalai Lama X (1995) The world of Tibetan buddhism: An overview of its philosophy and practice. Wisdom Publisher; Boston

Darwin C (1871) The descent of man, and selection in relation to sex. In: Moore J, Desmond A (eds) The descent of man, and selection in relation to sex. Penguin, New York

De Lange AH, Taris TW, Kompier MA, Houtman IL, Bongers PM (2004) The relationships between work characteristics and mental health: examining normal, reversed and reciprocal relationships in a 4 -wave study. Work Stress 18(2):149-166

Dembe AE, Delbos RG, Erickson JB (2008) The effect of occupation and industry on the injury risks from demanding work schedules. J Occup Environ Med 50:1185-1194

Department of Health (DOH) (2012) Caring for our future: reforming care and support. The Stationary Office, London

Department of Personnel and Training (DOPT), Government of India (2020) Annual General Bulletin; 25-70

Drent M, Lower EE, De Vries J (2012) Sarcoidosis-associated fatigue. Eur Respir J 40(1):255-263

Duan C, Hill CE (1996) The current state of empathy research. J Couns Psychol 43:261-274

Dutton DG (2006) The abusive personality: Violence and control in intimate relationships. Guilford Press

Dutton JE, Workman KM, Hardin AE (2014) Compassion at work. Annu Rev Organ Psych Organ Behav 1(1):277-304

Eldor L (2018) Public service sector: the compassionate workplace - the effect of compassion and stress on employee engagement burnout and performance. J Public Adm Res Theory 28(1):86-103

Elraz H (2017) Identity, mental health and work: How employees with mental health conditions recount stigma and the pejorative discourse of mental illness. Hum Relat 71(5):722-741

Erceg N, Ružojčić M, Galić Z (2020) Misbehaving in the Corona crisis: The role of anxiety and unfounded beliefs. Curr Psychol 33:1-3

Feldman C, Kuyken W (2011) Compassion in the landscape of suffering. Contemp Buddh 12(1):143-155

Folkard S, Tucker P (2003) Shift work, safety and productivity. Occup Med (lond) 53:95-101 
Frost PJ (1999) Why compassion counts! J Manag Inq 8:127-133

Frost P, Dutton JE, Worline M, Wilson A (2000) Narratives of compassion in organizations. In: Fineman S (ed) Emotions in organizations. Sage, London, pp 25-45

Galderisi S, Heinz A, Kastrup M, Beezhold J, Sartorius N (2015) Toward a new definition of mental health. World Psychiatry $14(2): 231$

Gilbert P (1984) Depression: from psychology to brain state. Lawrence Erlbaum Associates, London

Gilbert P (2000) The relationship of shame, social anxiety and depression: the role of the evaluation of social rank. Clin Psychol Psychother 7:174-189

Gilbert P (2009) The compassionate mind. Constable, London

Goetz J, Keltner D, Simon-Thomas E (2010) Compassion: an evolutionary analysis and empirical review. Psychol Bull 136:351-374

Hideg I, Ferris DL (2016) The compassionate sexist? How benevolent sexism promotes and undermines gender equality in the workplace. J Pers Soc Psychol 111(5): 706-727

Hwang JY, Plante T, Lackey K (2008) The development of the santa clara brief compassion scale: an abbreviation of sprecher and fehr's compassionate love scale. Pastor Psychol 56:421-428

Jacobson JM (2006) Compassion fatigue, compassion satisfaction, and burnout: reactions among employee assistance professionals providing workplace crisis intervention and disaster management services. J Work Behav Health 21:133-152

Kahn WA (1993) Caring for the caregivers: patterns of organizational caregiving. Adm Sci Q 38(4):539-563

Kaiser BN, Varma S, Carpenter-Song E, Sareff R, Rai S, Kohrt BA (2020) Eliciting recovery narratives in global mental health: Benefits and potential harms in service user participation. Psychiatric Rehabil J 43(2):111-120

Kamraju M (2021) A study on Covid-19 vaccination drive in India. BRICS J Educ Res 11(2):76-79

Kanov J, Maitlis S, Worline MC, Dutton JE, Frost PJ, Lilius J (2004) Compassion in organizational life. Am Behav Sci 47:808-827

Kanov J, Powley EH, Walshe ND (2017) Is it ok to care? How compassion falters and is courageously accomplished in the midst of uncertainty. Hum Relat 70:751-777

Karotia D, Kumar A (2020) A perspective on India's fight against COVID-19. Epidemiol Int 5:22-28

Kellett JB, Humphrey RH, Sleeth RG (2006) Empathy and the emergence of task and relations leaders. Leadersh Quart 17:146-162

Kniffin KM, Narayanan J, Anseel F, Antonakis J, Ashford SP, Bakker AB, Bamberger P, Bapuji H, Bhave DP, Choi VK, Creary SJ, Demerouti E, Flynn FJ, Gelfand MJ, Greer LL, Johns G, Kesebir S, Klein PG, Lee SY, Vugt MV (2021) COVID-19 and the workplace: Implications, issues, and insights for future research and action. Am Psychol 76(1):63-77

Kumar A, Somani A (2020) Dealing with Corona virus anxiety and OCD. Asian J Psychiatry 51

Lauber JK, Kayton PJ (1988) Sleepiness, circadian dysrhythmia, and fatigue in transportation system accidents. Sleep 11:503-512
Lazarus RS (1991) Emotion and adaptation. Oxford University Press, Oxford

Lee, S.A. (2020). Coronavirus Anxiety Scale: A brief mental health screener for COVID-19 related anxiety.

Li F, Luo S, Mu W, Li Y, Ye L, Zheng X, Chen X (2021) Effects of sources of social support and resilience on the mental health of different age groups during the COVID-19 pandemic. BMC Psychiatr 21(1):1-14

Lilius JM, Worline MC, Maitlis S, Kanov J, Dutton JE, Frost P (2008) The contours and consequences of compassion at work. J Organ Behav 29:193-218

Lilius JM, Kanov JM, Dutton JE (2011) Compassion revealed: What we know about compassion at work and where we need to know more. In: Cameron K, Spreitzer G (eds) Oxford Handbook of Positive Organizational Scholarship. Oxford University Press, New York

Lund, S., K.Ellingrud, B.Hancock, and J.Manyika. (2020). COVID-19 and Jobs: Monitoring the US Impact on People and Places. McKinsey Global Institute website.

Ma Y, Zhao Y, Liu J, He X, Wang B, Fu S, Yan J, Niu J, Zhou J, Luo B (2020) Effects of temperature variation and humidity on the death of COVID-19 in Wuhan, China. Sci Total Environ 724:138226

MacBeth A, Gumley A (2012) Exploring compassion: a metaanalysis of the association between self-compassion and psychopathology. Clin Psychol Rev 32(6):545-552

MacIntyrea CR (2020) On a knife's edge of a COVID-19 pandemic: is containment still possible? Public Health Res Pract 30:3012000

Madden LT, Duchon D, Madden TM, Plowman DA (2012) Emergent organizational capacity for compassion. Acad Manag Rev 37(4):689-708

Majumdar P, Biswas A, Sahu S (2020) COVID-19 pandemic and lockdown: cause of sleep disruption, depression, somatic pain, and increased screen exposure of office workers and students of India. Chronobiol Int 37(8):1191-1200

Manns ML, Little S (2011) Grief and compassion in the workplace. J Behav Stud Bus 4:1-13

Michie S, West R. (2020) Behavioural, environmental, social, and systems interventions against covid-19. BMJ, 370.

Miehielson H, De Vries J, Van Hock G (2003) Psychometric qualities of a brief self-rated fatigue measure: The Fatigue Assessment Scale. J Psychosom Res 54:345-352

Miller KI (2007) Compassionate communication in the workplace: exploring processes of noticing, connecting, and responding. J Appl Commun Res 35(3):223-245

Ministry of Health and Family Welfare (MOHFW), Government of India (2020). Telemedicine Practice Guidelines Enabling Registered Medical Practitioners to Provide Healthcare Using Telemedicine.

Mitler MM, Poceta JS, Bigby BG (1994) 12 - Sleep Scoring Technique. Sleep Disord Med, pp 151-164

Morgul E, Bener A, Atak M, Akyel S, Aktaş S, Bhugra D, Ventriglio A, Jordan TR (2021) COVID-19 pandemic and psychological fatigue in Turkey. Int $\mathrm{J}$ Soc Psychiatry 67(2):128-135

Nardi AE, Cosci F (2021) Expert opinion in anxiety disorder: Corona-phobia, the new face of anxiety. Personalized Med Psychiatry 25 
Neff K (2003a) Self-compassion: An alternative conceptualization of a healthy attitude toward oneself. Self Ident 2:85-101

Neff K (2003b) The development and validation of a scale to measure self-compassion. Self Ident 2:223-250

Neff K (2011) Self-compassion, self-esteem, and well-being. Soc Personal Compass 5(1):1-12

Newey, S. and Gulland, A. (2020). What is Coronavirus, how did it start and how big could it get? The Telegraph.

Newman SA, Ford RC (2021) Five Steps to Leading Your Team in the Virtual COVID-19 Workplace. Organ Dyn 50(1): 100802

Newton JL, Jones DE (2010) Making sense of fatigue. Occup Med (lond) 60:326-329

Noy YI, Horrey WJ, Popkin SM, Folkard S, Howarth HD, Courtney TK (2011) Future directions in fatigue and safety research. Accid Anal Prev 43(2):495-497

Nussbaum M (1996) Compassion: the basic social emotion. Soc Philos Policy 13(01):27

O'Brien PJ (2006) Creating compassion and connection in the work place. J Syst Ther 25(1):16-36

Pandey A, Saxena NK (2020) Effectiveness of government policies in controlling COVID-19 in India. Int $\mathbf{J}$ Health Serv 0(0):1-8

Pfefferbaum B, North CS (2020) Mental health and the Covid19 pandemic. N Engl J Med 383:510-512

Pommier E.A. (2010). The compassion scale, Dissertations \& Thesis.

Rofcanin Y, Anand S (2020) Human Relations virtual special issue: Flexible Work Practices and Work-Family Domain. Hum Relats 73(8):1182-1185

Rosekind M (1999) Fatigue in Transportation: Physiological, Performance and Safety Issues. Evaluation of US Department of Transportation Efforts in the 1990s to Address Operator Fatigue. Safety Report No. NTSB/SR-99/01. Washington DC

Rosekind M, Gregory KB, Mallis M, Brandt S, Seal B, Lerner D (2010) The cost of poor sleep: workplace productivity loss and associated costs. J Occup Environ Med 52:91-98

Rozin P (2001) Social psychology and science: some lessons from Soloman Asch. Personal Soc Psychol Rev: Special Issue 5:2-14

Sandelands LE (1998) Feeling and form in social life. Rowman and Littlefield, Lanham, MD

Sandelands LE (2003) Thinking about social life. University Press of America, Lanham, MD

Sasangohar H, Dhala A, Zheng F, Ahmadi N, Kash B, Masud F (2021) Use of telecritical care for family visitation to ICU during the COVID-19 pandemic: an interview study and sentiment analysis. BMJ Qual Saf 30(9):715-721

Selvi J (2020) Occupational Health Hazards among Women Workers in Healthcare Industry: An Analysis. Shanlax Int J Econ 8(2)

Seppala E, Cameron K (2015) Proof that positive work cultures are more productive. Harvard Bus Rev 12(1):44-50

Sharma V, Majumder P, Barman R (2020) Two tents for Corona Virus-mental health perspective. Int $\mathrm{J}$ Psychiatr Res $3(3): 1-3$

Shigemura J, Ursano RJ, Morganstein JC (2020) Public responses to the novel 2019 coronavirus $(2019-\mathrm{nCoV})$ in
Japan: mental health consequences and target populations. Psychiatr Clin Neurosci 74(4):281-282

Slemp GR, Vella-Brodrick DA (2014) Optimising employee mental health: the relationship between intrinsic need satisfaction, job crafting, and employee well-being. J Happiness Stud 15:957-977

Smith A (1759) In: Raphael DD, Macfie AL (eds) The Theory of Moral Sentiments. Indianapolis, Liberty Fund

Smith A. (1976) Raphael DD, Macfie AL (eds) The theory of moral sentiments. Clarendon Press, Oxford.

Sprang G, Clark J, Whitt-Woosley A (2007) Compassion fatigue, compassion satisfaction, and burnout: factors impacting a professional's quality of life. J Loss Trauma 12(3):259-280

Srivastava K, Chatterjee K, Bhat PS (2016) Mental health awareness: the Indian scenario. Ind Psychiatry J 25(2):131-134

Strauss C, Lever Taylor B, Gu J, Kuyken W, Baer R, Jones F, Cavanagh K (2016) What is compassion and how can we measure it? A review of definitions and measures. Clin Psychol Rev 47:15-27

Tilley AJ, Wilkinson RT, Drud M (1981) Night and day shifts compared in terms of the quality and quantity of sleep recorded in the home and performance measured at work: a pilot study. In: Reinberg A, Vieux N, Andlauer P (eds) Night and shiftwork: biological and social aspects. Pergamon, Oxford, pp 187-196

Tilley AJ, Wilkinson RT, Warren PSG, Watson WB, Drud M (1982) The sleep and performance of shiftworkers. Hum Factors 24:624-641

Tooze, A. (2020). Is the Coronavirus Crash Worse Than the 2008 Financial Crisis?. Foreign Policy.

Townsend L, Dowds J, O'Brien K, Sheill G, Dyer AH, O'Kelly B, Bannan C (2021) Persistent poor health after COVID-19 is not associated with respiratory complications or initial disease severity. Ann Amer Thorac Soc 18(6):997-1003

Veer, I., Riepenhausen, A., Zerban, M., Wackerhagen, C., Engen, H., Puhlmann, L. M. C., Köber, G., Van Leeuwen, J., Tüscher, O., Yuen, K. S. L., Walter, H., Kalisch, R. (2020). Mental resilience to stressor prevalence and severity during the Corona lockdown in Europe. Psychoneuroendocrinol, 119.

Vegso S, Cantley L, Slade M (2007) Extended work hours and risk of acute occupational injury: a case-crossover study of workers in manufacturing. Am J Ind Med 50:597-603

Weick KE, Sutcliffe KM, Obstfeld D (1999) Organizing for high reliability: processes of collective mindfulness. Res Organ Behav 21:81-123

Wong E, Ho KF, Wong SY, Cheung AW \& Yeoh E. (2020).Workplace safety and coronavirus disease (COVID-19) pandemic: survey of employees. [Preprint]. Bull World Health Organization. E-pub: 20 March 2020.

World Health Organization (WHO), Government of India (2014). Global Status Report on Non-Communicable Diseases; 22-51.

Wostyn P (2021) COVID-19 and chronic fatigue syndrome: Is the worst yet to come? Med Hypotheses 146:110469

Zabelina DL, Robinson MD (2010) Don't be so hard on yourself: Self-compassion facilitates creative originality among self-judgmental individuals. Creativity Res J 22(3): 288-293 
Zoghbi-Manrique-de-Lara P, Guerra-Báez RM (2018) A study of why anomic employees harm co-workers: do uncompassionate feelings matter? J Bus Ethics 152:1117-1132

Zoghbi-Manrique-de-Lara P, Viera-Armas M (2019) Does ethical leadership motivate followers to participate in delivering compassion? J Bus Ethics 154:195-210
Publisher's Note Springer Nature remains neutral with regard to jurisdictional claims in published maps and institutional affiliations. 